\title{
Coronavirus disease 2019 (COVID-19) and QTc prolongation
}

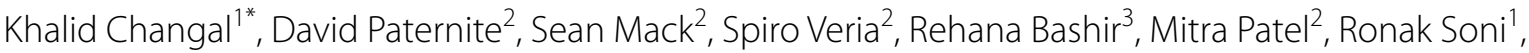 \\ Muhammad $\mathrm{Ali}^{4}$, Tanveer $\mathrm{Mir}^{5}$, Mujeeb Sheikh ${ }^{6 *}$ and P. Kasi Ramanathan ${ }^{6}$
}

\begin{abstract}
Introduction: The cause-and-effect relationship of QTc prolongation in Coronavirus disease 2019 (COVID-19) patients has not been studied well.

Objective: We attempt to better understand the relationship of QTC prolongation in COVID-19 patients in this study. Methods: This is a retrospective, hospital-based, observational study. All patients with normal baseline QTc interval who were hospitalized with the diagnosis of COVID-19 infection at two hospitals in Ohio, USA were included in this study.

Results: Sixty-nine patients had QTc prolongation, and 210 patients continued to have normal QTc during hospitalization. The baseline QTc intervals were comparable in the two groups. Patients with QTc prolongation were older (mean age 67 vs. 60, P 0.003), more likely to have underlying cardiovascular disease (48\% versus 26\%, P 0.001 ), ischemic heart disease (29\% versus 17\%, P 0.026), congestive heart failure with preserved ejection fraction (16\% versus $8 \%, \mathrm{P} 0.042)$, chronic kidney disease (23\% versus $10 \%, \mathrm{P} 0.005)$, and end-stage renal disease $(12 \%$ versus $1 \%, \mathrm{P}<0.001)$. Patients with QTc prolongation were more likely to have received hydroxychloroquine (75\% versus 59\%, P 0.018), azithromycin (18\% vs. 14\%, P 0.034), a combination of hydroxychloroquine and azithromycin ( $29 \%$ vs 7\%, P<0.001), more than 1 QT prolonging agents (59\% vs. 32\%, P<0.001). Patients who were on angiotensin-converting enzyme inhibitors (ACEi) were less likely to develop QTc prolongation (11\% versus 26\%, P 0.014 ). QTc prolongation was not associated with increased ventricular arrhythmias or mortality.

Conclusion: Older age, ESRD, underlying cardiovascular disease, potential virus mediated cardiac injury, and drugs like hydroxychloroquine/azithromycin, contribute to QTc prolongation in COVID-19 patients. The role of ACEi in preventing QTc prolongation in COVID-19 patients needs to be studied further.
\end{abstract}

Keywords: QT prolongation, COVID-19, Cardiovascular disease

*Correspondence: khalidchangal@gmail.com; Smujeeb73@gmail.com

${ }^{1}$ Cardiovascular Medicine, University of Toledo, Toledo, OH, USA

${ }^{6}$ Department of Cardiovascular Medicine and Interventional Cardiology,

Promedica Toledo Hospital, 2109 Hughes Dr, Jobst Tower 3rd, Floor,

Toledo, OH 43606, USA

Full list of author information is available at the end of the article

\section{Highlights}

- QTc prolongation is common in COVID-19 patients in a hospital setting.

- Older age, ESRD, underlying cardiovascular disease, potential virus mediated cardiac injury, and drugs like hydroxychloroquine/azithromycin, contribute to QTc prolongation in COVID-19 patients.

- QTc prolongation is related to adverse patient outcomes in COVID-19. 
- Angiotensin-converting enzyme (ACE) inhibitors need to be studied further for their role in preventing QTc prolongation in COVID-19 patients.

\section{Introduction}

In December 2019, the novel coronavirus-infected pneumonia (NCIP), started in Wuhan, China and spread worldwide to cause a pandemic [1-5]. Coronavirus disease 2019 (COVID-19) continues to affect the United States of America (USA) severely. As of 27 December 2020, the number of cases in the USA has reached $18,730,806$, the most of any country in the world. The number of deaths is 329,592 and continues to increase [6]. While the predominant reason for mortality and morbidity is respiratory involvement and failure [7]. The cardiovascular effects of COVID-19 include cardiac injury, myocarditis, cardiomyopathy, heart failure, arrhythmias, and thromboembolic phenomena [8-10]. QTc prolongation has been noticed in hospitalized COVID-19 patients. The cause-and-effect relationship of QTc prolongation in COVID-19 patients has not been studied well. We attempt to study this relationship in this retrospective study.

\section{Methods}

This is a retrospective, hospital-based, observational study. All patients who were hospitalized with the diagnosis of COVID-19 infection from 1 January 2020 through 1 May 2020 at two tertiary care hospitals in Toledo, Ohio were included in this study. Real-Time RTPCR (cobas ${ }^{\circledR}$ SARS-CoV-2 Test) was utilized for diagnosis in nasopharyngeal and oropharyngeal swab samples from patients. Patients less than 18 years old and those with history of QTc prolongation were excluded. History of QTc prolongation was defined as prolongation of QTc on an EKG done (when available) at least 4 weeks prior. If prior EKG was not available (18\% patients) the QTc was presumed to have been normal. All patients had an admission EKG. The normal QTc in men is less than $450 \mathrm{~ms}$ and less than $470 \mathrm{~ms}$ in women [11]. For the purpose of the study and to include true positive cases, QTc was considered prolonged if more than $460 \mathrm{~ms}$ in men and more than $480 \mathrm{~ms}$ in women on any EKG done during hospital stay. This cut off was used to allow for variations in measurement.

We collected data on demographics, comorbidities, electrocardiography (EKG), corrected QT interval, length of hospital stay, cost of hospitalization, in-patient mortality, and other clinical outcomes. The data was collected by reviewing the electronic medical records of the patients. The hospital system maintains elaborate medical records of all patients treated. We used Bazett's formula for measuring QTc. The QT intervals were measured manually using the tangent method and dividing by the square root of the RR interval preceding the QT interval. For patients with intraventricular conduction delays (bundle branch block, paced rhythms), a modified QTc was calculated using the formula: (QT-(QRS120msec)) $/ \sqrt{ } \mathrm{RR}$ [12]. All the EKGs done during the hospital stay were studied.

The data were analyzed using Statistical Package for the Social Sciences (SPSS), Version 20.0, from SPSS incorporation Chicago, IL. We used mean, standard deviation/ standard error of mean, and percentage when appropriate for the patient's characteristic description. Group differences were compared using the Pearson $\chi 2$ or Fisher's exact test for categorical variables, or the Student $t$ test or the Mann-Whitney $U$ test for continuous variables. $P$-values of 0.05 or less were considered statistically significant. We conducted univariate and multivariate regression analysis for factors contributing to QTc prolongation, and for the effect of QTc prolongation on different outcomes. In multivariate analysis, only the variables with statistical significance on univariate analysis were studied. Multivariate analysis was done separately for baseline comorbidities (7 variables) and for hospital course/clinical outcomes (7 variables).

The study was approved by the Institutional Review Board of Promedica Health System in Toledo, Ohio, USA.

\section{Results}

A total of 279 patients were included in this study. Sixtynine patients met the inclusion criteria of QTc prolongation, and 210 patients were included in the normal QTc group. The average baseline QTc on admission in all patients was $430 \pm 18 \mathrm{~ms}$. The baseline QTc in the two groups was comparable ( $431 \pm 20$ vs. $430 \pm 19 \mathrm{~ms}, \mathrm{P} 0.72$ ). The mean longest QTc in the QT prolongation group was $492 \pm 27.2 \mathrm{~ms}$ (range 462-600), and in the normal QT group was $431 \pm 25.7 \mathrm{~ms}(294-471)$. Baseline characteristics are described in Table 1. Patients with QTc prolongation were older (mean age 67 versus 60 years, P 0.003), more likely to have underlying cardiovascular disease (48\% versus $26 \%$, P 0.001), ischemic heart disease $(29 \%$ versus $17 \%, \mathrm{P} 0.026)$, congestive heart failure with preserved ejection fraction (16\% versus $8 \%, \mathrm{P} 0.042)$, chronic kidney disease (23\% versus $10 \%, \mathrm{P} 0.005)$, and end-stage renal disease $(E S R D)(12 \%$ versus $1 \%, P<0.001)$. Patients who were on angiotensin-converting enzyme inhibitors (ACEi) were less likely to develop QTc prolongation $(11 \%$ versus $26 \%$, P 0.014). No significant statistical difference was noticed for gender, race, hypertension, congestive heart failure with reduced ejection fraction, history of atrial fibrillation, stroke, or chronic liver disease. 
Table 1 Patient characteristics and comorbidities; comparison of patients with and without QTC prolongation on EKG

\begin{tabular}{|c|c|c|c|c|}
\hline Baseline characteristics & All patients $(\mathrm{N}=279)$ & QTc prolongation $(\mathrm{N}=69)$ & $\begin{array}{l}\text { No QTc prolongation } \\
(\mathrm{N}=210)\end{array}$ & $P$ value \\
\hline Baseline QTc (ms) & $430 \pm 18$ & $431 \pm 20$ & $430 \pm 19$ & 0.72 \\
\hline Age & $62 \pm 17$ & $67 \pm 17$ & $60 \pm 17$ & 0.003 \\
\hline \multicolumn{5}{|l|}{ Sex } \\
\hline Male, n (\%) & $145(52)$ & $39(57)$ & $106(51)$ & \multirow[t]{2}{*}{0.383} \\
\hline Female, $\mathrm{n}(\%)$ & $134(48)$ & $30(44)$ & $104(50)$ & \\
\hline \multicolumn{5}{|l|}{ Race } \\
\hline Caucasian, n (\%) & $181(65)$ & $40(58)$ & $141(68)$ & \multirow[t]{4}{*}{0.097} \\
\hline African-American, n (\%) & $82(30)$ & $27(39)$ & $55(26)$ & \\
\hline Latino, n (\%) & $13(5)$ & $1(1)$ & $12(6)$ & \\
\hline Other, n (\%) & $2(1)$ & $1(1)$ & $1(1)$ & \\
\hline Hypertension, n (\%) & $197(70)$ & $53(77)$ & $144(67)$ & 0.192 \\
\hline Diabetes mellitus, n (\%) & $101(36)$ & $31(45)$ & $70(33)$ & 0.082 \\
\hline Cardiovascular disease, n (\%) & $87(31)$ & $33(48)$ & $54(26)$ & 0.001 \\
\hline Ischemic heart disease, n (\%) & $55(20)$ & $20(29)$ & $35(17)$ & 0.026 \\
\hline CHFrEF, n (\%) & $13(5)$ & $5(7)$ & $8(4)$ & 0.240 \\
\hline CHFpEF, n (\%) & $27(10)$ & $11(16)$ & $16(8)$ & 0.042 \\
\hline Atrial fibrillation, n (\%) & $28(10)$ & $11(16)$ & $17(8)$ & 0.060 \\
\hline Active cancer, n (\%) & $12(4)$ & $3(4)$ & $9(4)$ & 0.982 \\
\hline Stroke, n (\%) & $33(12)$ & $8(12)$ & $25(12)$ & 0.945 \\
\hline Chronic kidney disease, n (\%) & $37(13)$ & $16(23)$ & $21(10)$ & 0.005 \\
\hline ESRD on HD, n (\%) & $11(4)$ & $8(12)$ & $3(1)$ & $<0.001$ \\
\hline Chronic liver disease, n (\%) & $13(5)$ & $6(9)$ & $7(3)$ & 0.062 \\
\hline Immunosuppressive state, n (\%) & $19(7)$ & $7(10)$ & $12(6)$ & 0.193 \\
\hline Home med: ACEi, n (\%) & $62(22)$ & $8(11)$ & $54(26)$ & 0.014 \\
\hline Home med: ARBs/ARNI, n (\%) & $32(12)$ & $8(12)$ & $24(11)$ & 0.970 \\
\hline
\end{tabular}

$\mathrm{CHFpEF}=$ congestive heart failure with preserved ejection fraction, $\mathrm{CHFrEF}=$ congestive heart failure with reduced ejection fraction, $\mathrm{ESRD}$ on $\mathrm{HD}=\mathrm{End}$ stage renal disease on hemodialysis, Immunosuppressive state = anyone on chronic immunomodulatory drugs or with immunodeficiencies such as $\mathrm{HIV}$, ARNI = Angiotensin Receptor-Neprilysin Inhibitor, EKG = Electrocardiogram

Table 2 describes the effect of QTc prolongation on hospital course and clinical outcomes. Patients with QTc prolongation were more likely to have another EKG abnormality also $(84 \%$ versus $21 \%, \mathrm{P}<0.001)$, first degree heart block ( $6 \%$ versus 1\%, P 0.016), new left or right bundle branch block $(20 \%$ vs. $5 \% \mathrm{P}<0.001)$, elevated troponin I (32\% versus $18 \%$, P 0.021 ), type 2 myocardial infarction (16\% versus $7 \%, P$ 0.029), and elevated creatinine (average of $2.5 \mathrm{mg} / \mathrm{dL}$ versus 1.6, P 0.004). Patients with QTc prolongation were more likely to have received hydroxychloroquine (75\% versus $59 \%, \mathrm{P}$ 0.018), azithromycin (18\% vs. $14 \%, \mathrm{P}$ 0.034), a combination of hydroxychloroquine and azithromycin $(29 \%$ vs $7 \%, \mathrm{P}<0.001)$, more than $1 \mathrm{QT}$ prolonging agent $(59 \%$ vs. $32 \%, \mathrm{P}<0.001)$. Patients with QTc prolongation were less likely to be discharged home and more likely to be discharged to a skilled nursing facility. Patients who continued to take ACEi while admitted were less likely to have QTc prolongation (7\% vs $18 \%$, P 0.037). There was no association between QTc prolongation and cardiac arrest, ventricular tachycardia, abnormal
BNP, elevated d-dimer, hypokalemia, hypomagnesemia, shock, acute respiratory distress syndrome, length of stay, cost of hospitalization, or death.

Univariate and Multivariate regression analysis were performed and are detailed in Table 3. On univariate analysis the odds of having QTc prolongation were higher with age (OR 1.03, 95\% CI 1.01-1.04), underlying cardiovascular disease (OR 2.60, 95\% CI 1.51-4.66), ischemic heart disease (OR 2.04, 95\% CI 1.08-3.85), congestive heart failure with preserved ejection fraction (OR 2.30, 95\% CI 1.01-5.23), chronic kidney disease (OR 2.72, 95\% CI 1.33-5.57), end stage renal disease (OR 9.05, 95\% CI 2.33-35.16). QTc prolongation was associated with higher odds of having a new left or right bundle branch block (OR 5.09, 95\% CI 2.14-12.08), any arrhythmia during hospitalization (OR 3.00, 95\% CI 1.49-6.02), elevated troponin (OR 2.08, 95\% CI 1.11-3.90), and type 2 myocardial infarction (OR 2.46, 95\% CI 1.07-5.66). The odds of developing QTc prolongation were higher with the use of hydroxychloroquine (OR 2.10, 95\% CI 1.20-3.80), 
Table 2 Patient outcomes and laboratory studies during hospitalization, and comparison of patients with and without QTC prolongation on EKG

\begin{tabular}{|c|c|c|c|c|}
\hline Clinical course/outcome & All patients $(\mathrm{N}=279)$ & QTc prolongation $(\mathrm{N}=69)$ & No QTc prolongation $(\mathrm{N}=210)$ & $P$ value \\
\hline Longest QTc measurement (msec) & $446 \pm 37$ & $492 \pm 27.2(462-600)$ & $431 \pm 25.7(294-471)$ & $<0.001$ \\
\hline Cardiac arrest, $n(\%)$ & $1(0.4)$ & 0 & $1(0.5)$ & 0.566 \\
\hline \multicolumn{5}{|l|}{ EKG \& cardiac rhythm abnormalities } \\
\hline Atrial fibrillation, n (\%) & $25(9)$ & $9(13)$ & $16(8)$ & 0.175 \\
\hline Sustained VT, n (\%) & $4(1)$ & $2(3)$ & $2(1)$ & 0.240 \\
\hline 1st degree heart block, n (\%) & $6(2)$ & $4(6)$ & $2(1)$ & 0.016 \\
\hline 2nd (Type 2) or 3rd degree heart block, n (\%) & $2(1)$ & $1(1)$ & $1(1)$ & 0.406 \\
\hline New left or right bundle branch block, n (\%) & $24(9)$ & $14(20)$ & $10(5)$ & $<0.001$ \\
\hline Abnormal EKG, n (\%) & $102(37)$ & $58(84)$ & $44(21)$ & $<0.001$ \\
\hline Any arrhythmia, n (\%) & $40(14)$ & $18(26)$ & $22(11)$ & 0.001 \\
\hline High troponin I, n (\%) & $58(22)$ & $21(32)$ & $37(18)$ & 0.021 \\
\hline Troponin I peak (ng/mL) & $0.34 \pm 1.50$ & $0.86 \pm 2.60$ & $0.16 \pm 0.88$ & 0.001 \\
\hline Abnormal BNP, n (\%) & $45(30)$ & $14(33)$ & $31(28)$ & 0.640 \\
\hline BNP peak (pg/mL) & $185 \pm 299$ & $277 \pm 427$ & $154 \pm 236$ & 0.064 \\
\hline High d-dimer, $n(\%)$ & $193(73)$ & $54(82)$ & $139(70)$ & 0.052 \\
\hline D-dimer peak (ng/mL) & $3254 \pm 8868$ & $3979 \pm 9035$ & $3019 \pm 8824$ & 0.463 \\
\hline Acute myocardial infarction (not Type 2), n (\%) & $2(1)$ & $0(0)$ & $2(1)$ & 0.416 \\
\hline Type 2 myocardial infarction, n (\%) & $26(9)$ & $11(16)$ & $15(7)$ & 0.029 \\
\hline Acute kidney injury, n (\%) & $111(40)$ & $34(49)$ & $77(37)$ & 0.063 \\
\hline Peak creatinine (mg/dL) & $1.85 \pm 2.15$ & $2.50 \pm 2.90$ & $1.60 \pm 1.80$ & 0.004 \\
\hline New HD or CVVHD, n (\%) & $7(3)$ & $2(3)$ & $5(2)$ & 0.811 \\
\hline Hypokalemia, n (\%) & $44(16)$ & $15(22)$ & $29(14)$ & 0.117 \\
\hline Hypomagnesemia, n (\%) & $39(14)$ & $11(16)$ & $18(13)$ & 0.558 \\
\hline Invasive ventilation, n (\%) & $52(19)$ & $14(20)$ & $38(18)$ & 0.685 \\
\hline Shock of any type, n (\%) & $45(16)$ & $10(15)$ & $35(17)$ & 0.692 \\
\hline ARDS, n (\%) & $43(16)$ & $5(7)$ & $38(18)$ & 0.032 \\
\hline Ischemic Stroke, n (\%) & $2(1)$ & $0(0)$ & $2(1)$ & 0.415 \\
\hline DVT and/or PE, n (\%) & $11(4)$ & $2(3)$ & $9(4)$ & 0.603 \\
\hline Death, n (\%) & $42(15)$ & $14(21)$ & $28(13)$ & 0.151 \\
\hline \multicolumn{5}{|l|}{ Discharge } \\
\hline Home, n (\%) & $74(62)$ & $33(48)$ & $141(67)$ & 0.023 \\
\hline SNF, n (\%) & $60(22)$ & $21(30)$ & $39(19)$ & \\
\hline LOS (days) & $9 \pm 9$ & $10 \pm 11$ & $9 \pm 8$ & 0.572 \\
\hline Cost of hospitalization (US dollars) & $92,973 \pm 125,980$ & $94,889 \pm 126,219$ & $87,142 \pm 125,990$ & 0.658 \\
\hline Hydroxychloroquine, n (\%) & $177(63)$ & $52(75)$ & $125(59)$ & 0.018 \\
\hline Azithromycin, n (\%) & $27(10)$ & $13(18)$ & $14(7)$ & 0.034 \\
\hline Hydroxychloroquine AND Azithromycin, n (\%) & $35(13)$ & $20(29)$ & $15(7)$ & $<0.001$ \\
\hline > 1 QT prolonging drug, n (\%) & $108(39)$ & $41(59)$ & $67(32)$ & $<0.001$ \\
\hline In hospital: ACEi/ARNI, n (\%) & $42(15)$ & $5(7)$ & $37(18)$ & 0.037 \\
\hline In hospital: ARBs, n (\%) & $32(12)$ & $9(13)$ & $23(11)$ & 0.636 \\
\hline
\end{tabular}

Sl units for $B N P(p m o l / L)=n g / m L * 3.46$

Sl units for creatinine $(\mu \mathrm{mol} / \mathrm{L})=\mathrm{mg} / \mathrm{dL} * 88.4$

SI units for troponin I $(\mu \mathrm{g} / \mathrm{L})=\mathrm{ng} / \mathrm{ml} * 1$

$\mathrm{ARNI}=$ angiotensin receptor-neprilysin inhibitor, $\mathrm{VT}=$ ventricular tachycardia, $\mathrm{ARDS}=$ acute respiratory distress syndrome, $\mathrm{PE}=$ pulmonary embolism, $\mathrm{HD}=$ hemodialysis, $\mathrm{CVVD}=$ continuous venovenous hemodialysis, $\mathrm{SNF}=$ skilled nursing facility, LOS = length of stay 
Table 3 Univariate and multivariate analysis for factors associated with QTc prolongation

\begin{tabular}{|c|c|c|c|c|c|c|}
\hline \multirow[t]{2}{*}{ Clinical factors } & \multicolumn{3}{|c|}{ Univariate analysis } & \multicolumn{3}{|c|}{ Multivariate analysis } \\
\hline & Odds ratio & $\begin{array}{l}95 \% \text { confidence } \\
\text { interval }\end{array}$ & $P$ value & Odds ratio & $\begin{array}{l}95 \% \text { confidence } \\
\text { interval }\end{array}$ & $P$ value \\
\hline Age & 1.03 & $1.01-1.04$ & 0.003 & 1.01 & $0.99-1.04$ & 0.210 \\
\hline Female sex & 0.78 & $0.45-1.36$ & 0.384 & - & - & - \\
\hline Hypertension & 1.52 & $0.81-2.85$ & 0.194 & - & - & - \\
\hline Diabetes mellitus & 1.63 & $0.94-2.84$ & 0.083 & - & - & - \\
\hline Cardiovascular disease & 2.65 & $1.51-4.66$ & 0.001 & 1.58 & $0.47-5.38$ & 0.464 \\
\hline Ischemic heart disease & 2.04 & $1.08-3.85$ & 0.027 & 0.81 & $0.25-2.66$ & 0.730 \\
\hline CHFrEF & 1.97 & $0.62-6.24$ & 0.248 & - & - & - \\
\hline CHFpEF & 2.30 & $1.01-5.23$ & 0.047 & 1.03 & $0.31-3.44$ & 0.965 \\
\hline Atrial fibrillation & 2.15 & $0.96-4.86$ & 0.065 & - & - & - \\
\hline Chronic kidney disease & 2.72 & $1.33-5.57$ & 0.006 & 1.37 & $0.55-3.42$ & 0.495 \\
\hline ESRD on $\mathrm{HD}$ & 9.05 & $2.33-35.16$ & 0.001 & 7.70 & $1.63-36.25$ & 0.010 \\
\hline Peak creatinine & 1.17 & $1.04-1.32$ & 0.008 & - & - & - \\
\hline Chronic liver disease & 2.81 & $0.91-8.66$ & 0.073 & - & - & - \\
\hline \multicolumn{7}{|l|}{ Home medication } \\
\hline ACEi & 0.38 & $0.17-0.84$ & 0.017 & 0.24 & $0.09-0.63$ & 0.004 \\
\hline ARBs/ARNi & 1.02 & $0.43-2.38$ & 0.970 & - & - & - \\
\hline \multicolumn{7}{|l|}{ Hospital course and clinical outcome } \\
\hline \multicolumn{7}{|l|}{ EKG findings } \\
\hline Atrial fibrillation & 1.81 & $0.76-4.30$ & 0.180 & - & - & - \\
\hline Sustained VT & 3.09 & $0.43-22.36$ & 0.264 & - & - & - \\
\hline New BBB & 5.09 & $2.14-12.09$ & $<0.001$ & 5.20 & $1.72-15.67$ & 0.003 \\
\hline Arrhythmia on admission & 0.99 & $0.90-1.08$ & 0.739 & - & - & - \\
\hline Arrhythmia in hospital course & 3.00 & $1.50-6.02$ & 0.002 & 1.70 & $0.43-2.67$ & 0.886 \\
\hline High troponin I & 2.08 & $1.11-3.90$ & 0.022 & 2.11 & $0.93-4.80$ & 0.982 \\
\hline Abnormal BNP & 1.20 & $0.56-2.57$ & 0.640 & - & - & - \\
\hline High d-dimer & 1.98 & $0.99-3.95$ & 0.055 & - & - & - \\
\hline Type 2 myocardial infarction & 2.47 & $1.07-5.66$ & 0.033 & 2.71 & $0.89-8.24$ & 0.079 \\
\hline Death & 1.68 & $0.82-3.41$ & 0.154 & - & - & - \\
\hline Cost of hospitalization & 1.00 & $1.00-1.00$ & 0.658 & - & - & - \\
\hline In hospital: ACEi & 0.37 & $0.12-0.97$ & 0.043 & - & - & - \\
\hline Hydroxychloroquine & 2.10 & $1.20-3.80$ & 0.019 & 2.49 & $1.23-5.02$ & 0.028 \\
\hline Azithromycin & 3.25 & $1.44-7.32$ & 0.041 & 2.87 & $1.11-9.23$ & 0.045 \\
\hline Hydroxychloroquine AND Azithromycin & 5.31 & $2.53-11.11$ & 0.026 & 4.14 & $1.09-15.72$ & 0.037 \\
\hline$>1$ QT prolonging drug & 3.03 & $1.70-5.40$ & $<0.001$ & - & - & - \\
\hline
\end{tabular}

$\mathrm{CHFpEF}=$ congestive heart failure with preserved ejection fraction, $\mathrm{CHFrEF}=$ congestive heart failure with reduced ejection, ARNI = angiotensin receptor-neprilysin inhibitor, $\mathrm{ESRD}$ on $\mathrm{HD}=$ end stage renal disease on hemodialysis, $\mathrm{VT}$ = ventricular tachycardia, $\mathrm{BBB}$ = bundle branch block (complete left or right),

azithromycin (OR 3.25, 95\% CI 1.44-7.32), and combined use of hydroxychloroquine and azithromycin (OR $5.31,95 \%$ CI 2.53-11.10).

On multivariate analysis the association of QTc prolongation with end stage renal disease, new bundle branch block, use of hydroxychloroquine, azithromycin, and combination use of azithromycin and hydroxychloroquine was confirmed. The odds of having QTc prolongation were lower with the use of ACEi in both univariate and multivariate analysis.

\section{Discussion}

Our study found QTc prolongation in one-fourth of the hospitalized COVID-19 patients. The factors strongly associated with QTc prolongation are ESRD, use of hydroxychloroquine, and/or azithromycin, older age, underlying cardiovascular disease, elevated troponin, type 2 MI, other EKG abnormalities, and new bundle branch block. Use of ACEi decreased the odds of developing QTc prolongation. QTc prolongation was not found to increase the risk of developing ventricular tachycardia 
or death and was not associated with increased cost of hospitalization. However, QTc prolongation was associated with more discharges to skilled nursing facilities than to home.

Our study indicates that QTc prolongation in COVID19 patients is likely related to an interplay between patient-related factors, administration of therapeutic agents, and the disease itself. In the absence of definitive curative therapies, hydroxychloroquine and azithromycin have been used to treat COVID-19 patients [13-15]. However, the recent RECOVERY trial (Randomized evaluation of COVID-19 therapy) failed to show any benefit of hydroxychloroquine in COVID-19 patients and on the contrary showed some signals towards harm [16]. Some recent observational studies have also pointed to the association of QTc prolongation in COVID-19 with the use of hydroxychloroquine and/or azithromycin [17-20]. Our study provides further evidence to the association of QTc prolongation with the use of hydroxychloroquine and azithromycin in this population. In the absence of clear benefit, these drugs are being avoided now, especially in patients with other risk factors for QTc prolongation. If they are used, QTc must be monitored closely. This is the first study to demonstrate a protective effect of ACEi on prolongation of QTC in COVID-19. While there is evidence to suggest that ACEi may reduce QT dispersion in heart failure and reduce QT interval in hypertension [21, 22], the effect of ACEi on QTc in COVID-19 has not been studied. In animal models, rats with hypertension had reduction in QT interval with ACEi but not with calcium channel blockers [22]. Previous studies showed ACEi increase the expression of ACE2, a cellular receptor for SARS-CoV-2 [23-25]. COVID-19 causes a severe acute respiratory syndrome by binding target epithelial lung cells through angiotensin-converting enzyme 2 (ACE2) in humans, provoking a concern that the use of ACEi might lead to increased mortality and severity of COVID-19 [26, 27]. Recent evidence has disproven this concern [25]. Patients with hypertension with COVID-19 could have worse prognosis. The benefits of ACE inhibitors/ARBs in COVID-19 could outweigh the risks and should not be withheld [27]. Whether the effect of ACEi on QTc in COVID-19 can be replicated in larger studies, and the mechanism involved needs to be evaluated. The benefits of ACE inhibitors/ARBs in COVID-19 could outweigh the risks and should not be withheld [27].

The possible patient-related factors associated with QTc prolongation in our study include older age, ESRD, and underlying cardiovascular disease. Older age was found to be associated with QTc prolongation in another study also [20]. ESRD was associated QTc prolongation. This can be explained by poor renal excretion of hydroxychloroquine in these patients $[28,29]$. Although, hypocalcemia was not studied by us, this could be seen in ESRD and may contribute to QTc prolongation. The association of troponin elevation and type $2 \mathrm{MI}$ can be due to ischemia contributing to QTc prolongation. We found diabetes mellitus in more patients with QTc prolongation than those with normal QTc but was not statistically significant. Diabetes is a poor prognostic factor for patients with COVID-19 [30, 31]. The (chronic and acute) hyperglycemia could negatively affect clinical outcomes and reduce the response to anti-SARS-COV2 therapies [32, 33]. In patients without viral disease and stable condition, the hyperglycemia is a negative factor to cause prolonged QTc interval with alteration of ventricular refractoriness and ventricular arrhythmias [34]. The overall increased risk of arrhythmias and other EKG abnormalities point to electrical instability of the myocardium in COVID19 patients. There seems to be a complex interplay of multiple factors contributing to or arising from QTc prolongation.

The study did not find an association between torsades de pointes and QTc prolongation. Considering the sample size, the study is likely underpowered to determine this. Other observational studies also have failed to show this association but are limited by small sample size [15-19].

The pathophysiology of cardiac involvement in COVID-19 infection has been thought to be due to direct invasion of virus into the cardiac tissue, and indirectly from the effects of inflammation. SARS-CoV binds to cells expressing appropriate viral receptors, particularly ACE2, which is abundant in the heart [10].

This study has certain limitations. This is an observational study which is prone to multiple biases. However, in the absence of randomized control trials and in the presence of an ongoing pandemic this study provides useful information. There was no preformed protocol for QTc monitoring in these patients and the decision relied on physician judgement. The patients who received QTc prolonging medications could have had their QTc interval monitored more closely than others. However, on our chart review we found uniform number of EKGs done in most patients. All patients in this study had continuous telemetry monitoring. Long-term follow-up is not available for these patients as this study was done on a hospitalized patient population.

To conclude, QTc prolongation is common in COVID19 patients. Interplay of multiple factors possibly contribute to this phenomenon. Hydroxychloroquine and azithromycin cause QTc prolongation in this patient population. Older age, ESRD, and underlying cardiovascular disease are risk factors for QTc prolongation. ACEi may prevent QTc prolongation in COVID-19 patients and this needs to be studied further. 


\section{Acknowledgements \\ None.}

\section{Authors' contributions}

KC: Concept, design, data collection, data analysis, manuscript writing/editing. DP, SM, SV, RB: Data collection, manuscript editing and review. MP, RS, MA, TM: Review of data, manuscript editing, critical review. MS, PKR: Senior authors, concept, design, manuscript review and editing. All authors read and approved the final manuscript.

\section{Funding}

None.

\section{Availability of data and materials}

The datasets used and/or analysed during the current study available from the corresponding author on reasonable request.

\section{Declarations}

\section{Ethics approval and consent to participate}

IRB approval was obtained from Promedica Health system in Toledo, $\mathrm{OH}$, USA. The study protocol was carried out in accordance with the Declaration of Helsinki. Obtained from IRB Promedica Health system in Toledo, OH, USA. Was waived by the IRB Promedica Health system in Toledo, $\mathrm{OH}$, USA due to retrospective design of the study.

\section{Consent for publication}

Not applicable.

\section{Competing interests}

None.

\section{Author details}

${ }^{1}$ Cardiovascular Medicine, University of Toledo, Toledo, OH, USA. ${ }^{2}$ University of Toledo College of Medicine and Life Sciences, Toledo, USA. ${ }^{3}$ Owen's Community College, Toledo, OH, USA. ${ }^{4}$ Internal Medicine, University of Toledo, Toledo, OH, USA. ${ }^{5}$ Internal Medicine, Detroit Medical Center, Wayne State University, Detroit, MI, USA. ${ }^{6}$ Department of Cardiovascular Medicine and Interventional Cardiology, Promedica Toledo Hospital, 2109 Hughes Dr, Jobst Tower 3rd, Floor, Toledo, OH 43606, USA.

Received: 18 February 2021 Accepted: 23 March 2021

Published online: 30 March 2021

\section{References}

1. Lu H, Stratton CW, Tang YW. Outbreak of pneumonia of unknown etiology in Wuhan China: the mystery and the miracle. J Med Virol. 2020. https://doi.org/10.1002/jmv.25678.

2. Hui DS, Azhar E, Madani TA, et al. The continuing 2019-nCoV epidemic threat of novel coronaviruses to global health: the latest 2019 novel coronavirus outbreak in Wuhan. China Int J Infect Dis. 2020;91:264-6. https:// doi.org/10.1016/j.jijid.2020.01.009.

3. Wuhan Municipal Health Commission. Report of novel coronavirusinfected pneumonia in China. Published January 20, 2020. Accessed 31 Jan 2020. http://wjw.wuhan.gov.cn/front/web/showDetail/2020012009 077.

4. Paules $\mathrm{Cl}$, Marston HD, Fauci AS. Coronavirus infections-more than just the common cold. JAMA. 2020. https://doi.org/10.1001/jama.2020.0757.

5. Wuhan Municipal Health Commission. Report of clustering pneumonia of unknown etiology in Wuhan City. Published December 31, 2019. http:// wjw.wuhan.gov.cn/front/web/showDetail/2019123108989.

6. Center for disease control. Accessed on 27 Dec 2020. https://www.cdc. gov/coronavirus/2019-ncov/cases-updates/cases-in-us.html\#1.

7. Wang D, Hu B, Hu C, Zhu F, Liu X, Zhang J, Wang B, Xiang H, Cheng Z, Xiong Y, Zhao Y. Clinical characteristics of 138 hospitalized patients with 2019 novel coronavirus-infected pneumonia in Wuhan, China. JAMA. 2020;323(11):1061-9.
8. Clerkin KJ, Fried JA, Raikhelkar J, Sayer G, Griffin JM, Masoumi A, Jain SS, Burkhoff D, Kumaraiah D, Rabbani L, Schwartz A. Coronavirus disease 2019 (COVID-19) and cardiovascular disease. Circulation. 2020.

9. Nishiga M, Wang DW, Han Y, Lewis DB, Wu JC. COVID-19 and cardiovascular disease: from basic mechanisms to clinical perspectives. Nat Rev Cardiol. 2020;17(9):543-58. https://doi.org/10.1038/s41569-020-0413-9.

10. Kwenandar F, Japar KV, Damay V, Hariyanto TI, Tanaka M, Lugito N, Kurniawan A. Coronavirus disease 2019 and cardiovascular system: a narrative review. IJC Heart Vasc. 2020;29:100557.

11. Goldenberg I, Moss AJ, Zareba W. QT interval: how to measure it and what is "normal." J Cardiovasc Electrophysiol. 2006;17:333-6.

12. Rautaharju PM, Surawicz B, Gettes LS, Bailey JJ, Childers R, Deal BJ, Gorgels A, Hancock EW, Josephson M, Kligfield P, Kors JA, Macfarlane P, Mason JW, Mirvis DM, Okin P, Pahlm O, van Herpen G, Wagner GS, Wellens H; American Heart Association Electrocardiography and Arrhythmias Committee, Council on Clinical Cardiology; American College of Cardiology Foundation; Heart Rhythm Society. AHA/ACCF/HRS recommendations for the standardization and interpretation of the electrocardiogram: part IV: the ST segment, T and U waves, and the QT interval: a scientific statement from the American Heart Association Electrocardiography and Arrhythmias Committee, Council on Clinical Cardiology; the American College of Cardiology Foundation; and the Heart Rhythm Society. Endorsed by the International Society for Computerized Electrocardiology. J Am Coll Cardiol. 2009;53(11):982-91. https://doi.org/10.1016/j.jacc.2008.12.014.

13. Rosenke K, Jarvis MA, Feldmann F, et al. Hydroxychloroquine proves ineffective in hamsters and macaques infected with SARS-CoV-2. bioRxiv. 2020. https://doi.org/10.1101/2020.06.10.145144.

14. Gautret $P$, Lagier J-C, Parola P, et al. Hydroxychloroquine and azithromycin as a treatment of COVID-19: results of an open-label non-randomized clinical trial. Int J Antimicrob Agents. 2020;56:105949-105949.

15. Gautret $P$, Lagier J-C, Parola $P$, et al. Clinical and microbiological effect of a combination of hydroxychloroquine and azithromycin in 80 COVID-19 patients with at least a six-day follow up: a pilot observational study. Travel Med Infect Dis. 2020;34:101663-101663.

16. RECOVERY Collaborative Group, Horby P, Mafham M, Linsell L, Bell JL, Staplin N, Emberson JR, Wiselka M, Ustianowski A, Elmahi E, Prudon B, Whitehouse T, Felton T, Williams J, Faccenda J, Underwood J, Baillie JK, Chappell LC, Faust SN, Jaki T, Jeffery K, Lim WS, Montgomery A, Rowan K, Tarning J, Watson JA, White NJ, Juszczak E, Haynes R, Landray MJ. Effect of Hydroxychloroquine in Hospitalized Patients with Covid-19. N Engl J Med. 2020;383(21):2030-40. https://doi.org/10.1056/NEJMoa2022926.

17. Bernardini A, Ciconte G, Negro G, Rondine R, Mecarocci V, Viva T, Santini F, de Innocentiis C, Giannelli L, Witkowska E, Locati ET, Castelvecchio S, Marrocco-Trischitta MM, Vicedomini G, Menicanti L, Pappone C. Assessing QT interval in COVID-19 patients: safety of hydroxychloroquine-azithromycin combination regimen. Int J Cardiol. 2020;S0167-5273(20):33819-25. https://doi.org/10.1016/j.ijcard.2020.09.038.

18. Saleh M, Gabriels J, Chang D, Soo Kim B, Mansoor A, Mahmood E, Makker P, Ismail H, Goldner B, Willner J, Beldner S, Mitra R, John R, Chinitz J, Skipitaris N, Mountantonakis S, Epstein LM. Effect of chloroquine, hydroxychloroquine, and azithromycin on the corrected QT interval in patients With SARS-CoV-2 infection. Circ Arrhythm Electrophysiol. 2020;13(6):e008662. https://doi.org/10.1161/CIRCEP.120.008662.

19. Chorin E, Wadhwani L, Magnani S, Dai M, Shulman E, Nadeau-Routhier C, Knotts R, Bar-Cohen R, Kogan E, Barbhaiya C, Aizer A, Holmes D, Bernstein S, Spinelli M, Park DS, Stefano C, Chinitz LA, Jankelson L. QT interval prolongation and torsade de pointes in patients with COVID-19 treated with hydroxychloroquine/azithromycin. Heart Rhythm. 2020;17(9):1425-33. https://doi.org/10.1016/j.hrthm.2020.05.014.

20. O'Connell TF, Bradley CJ, Abbas AE, Williamson BD, Rusia A, Tawney AM, Gaines R, Schott J, Dmitrienko A, Haines DE. Hydroxychloroquine/ azithromycin therapy and QT prolongation in hospitalized patients with COVID-19. JACC Clin Electrophysiol. 2020. https://doi.org/10.1016/j.jacep. 2020.07.016.

21. Ranade V, Molnar J, Khokher T, Agarwal A, Mosnaim A, Somberg JC. Effect of angiotensin-converting enzyme therapy on QT interval dispersion. Am J Ther. 1999;6(5):257-61. https://doi.org/10.1097/00045391-19990 9000-00005.

22. Klimas J, Vaja V, Vercinska M, Kyselovic J, Krenek P. Discrepant regulation of QT (QTC) interval duration by calcium channel blockade and angiotensin converting enzyme inhibition in experimental hypertension. Basic Clin 
Pharmacol Toxicol. 2012;111(4):279-88. https://doi.org/10.1111/j.17427843.2012.00901.x.

23. Ferrario CM, Jessup J, Chappell MC, et al. Effect of angiotensin-converting enzyme inhibition and angiotensin II receptor blockers on cardiac angiotensin-converting enzyme 2. Circulation. 2005;111(20):2605-10.

24. Soler MJ, Ye M, Wysocki J, William J, Lloveras J, Batlle D. Localization of ACE2 in the renal vasculature: amplification by angiotensin II type 1 receptor blockade using telmisartan. Am J Physiol Renal Physiol. 2009;296(2):F398-405

25. Wang $X, Y e Y$, Gong $H$, et al. The effects of different angiotensin II type 1 receptor blockers on the regulation of the ACE-Angll-AT1 and ACE2Ang(1-7)-Mas axes in pressure overload-induced cardiac remodeling in male mice. J Mol Cell Cardiol. 2016;97:180-90.

26. Sardu C, Marfella R, Maggi P, et al. Implications of ABO blood group in hypertensive patients with covid-19. BMC Cardiovasc Disord. 2020;20:373. https://doi.org/10.1186/s12872-020-01658-z.

27. Sardu C, Maggi P, Messina V, luliano P, Sardu A, lovinella V, Paolisso G, Marfella R. Could anti-hypertensive drug therapy affect the clinical prognosis of hypertensive patients with COVID-19 infection? Data from centers of Southern Italy. J Am Heart Assoc. 2020;9(17):e016948. https://doi.org/10. 1161/JAHA.120.016948.

28. Browning DJ. Pharmacology of chloroquine and hydroxychloroquine. hydroxychloroquine and chloroquine retinopathy. 2014:35-63. https:// doi.org/10.1007/978-1-4939-0597-3_2.

29. Chorin E, Dai M, Shulman E, Wadhwani L, Bar-Cohen R, Barbhaiya C, Aizer A, Holmes D, Bernstein S, Spinelli M, Park DS, Chinitz LA, Jankelson L. The QT interval in patients with COVID-19 treated with hydroxychloroquine and azithromycin. Nat Med. 2020;26(6):808-9. https://doi.org/10.1038/ s41591-020-0888-2
30. Sardu C, D'Onofrio N, Balestrieri ML, Barbieri M, Rizzo MR, Messina V, Maggi P, Coppola N, Paolisso G, Marfella R. Outcomes in patients with hyperglycemia affected by COVID-19: can we do more on glycemic control? Diabetes Care. 2020;43(7):1408-15. https://doi.org/10.2337/ dc20-0723.

31. Sardu C, Gargiulo G, Esposito G, Paolisso G, Marfella R. Impact of diabetes mellitus on clinical outcomes in patients affected by Covid-19. Cardiovasc Diabetol. 2020;19(1):76. https://doi.org/10.1186/s12933-020-01047-y.

32. Marfella R, Paolisso P, Sardu C, Bergamaschi L, D'Angelo EC, Barbieri M, Rizzo MR, Messina V, Maggi P, Coppola N, Pizzi C, Biffi M, Viale P, Galié N, Paolisso G. Negative impact of hyperglycaemia on tocilizumab therapy in Covid-19 patients. Diabetes Metab. 2020;46(5):403-5. https://doi.org/10. 1016/j.diabet.2020.05.005.

33. Sardu C, D'Onofrio N, Balestrieri ML, Barbieri M, Rizzo MR, Messina V, Maggi P, Coppola N, Paolisso G, Marfella R. Hyperglycaemia on admission to hospital and COVID-19. Diabetologia. 2020;63(11):2486-7. https://doi. org/10.1007/s00125-020-05216-2.

34. Santulli G, Pagano G, Sardu C, Xie W, Reiken S, D'Ascia SL, Cannone M, Marziliano N, Trimarco B, Guise TA, Lacampagne A, Marks AR. Calcium release channel RyR2 regulates insulin release and glucose homeostasis. J Clin Invest. 2015;125(5):1968-78. https://doi.org/10.1172/JCl79273.

\section{Publisher's Note}

Springer Nature remains neutral with regard to jurisdictional claims in published maps and institutional affiliations.
Ready to submit your research? Choose BMC and benefit from:

- fast, convenient online submission

- thorough peer review by experienced researchers in your field

- rapid publication on acceptance

- support for research data, including large and complex data types

- gold Open Access which fosters wider collaboration and increased citations

- maximum visibility for your research: over 100M website views per year

At BMC, research is always in progress.

Learn more biomedcentral.com/submissions 